ARTICLE

\title{
Electro-reduction of carbon dioxide at low over-potential at a metal-organic framework decorated cathode
}

Xinchen Kang (10) 1, Lili Li', Alena Sheveleva (10 1, Xue Han', Jiangnan Li', Lifei Liu², Floriana Tuna (1) 1,3,

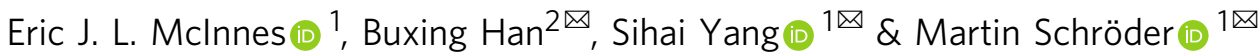

Electrochemical reduction of carbon dioxide is a clean and highly attractive strategy for the production of organic products. However, this is hindered severely by the high negative potential required to activate carbon dioxide. Here, we report the preparation of a copperelectrode onto which the porous metal-organic framework $\left[\mathrm{Cu}_{2}(\mathrm{~L})\right]\left[\mathrm{H}_{4} \mathrm{~L}=4,4^{\prime}, 4^{\prime \prime}, 4^{\prime \prime \prime}\right.$ - $(1,4-$ phenylenebis(pyridine-4,2,6-triyl))tetrabenzoic acid] can be deposited by electro-synthesis templated by an ionic liquid. This decorated electrode shows a remarkable onset potential for reduction of carbon dioxide to formic acid at $-1.45 \mathrm{~V}$ vs. $\mathrm{Ag} / \mathrm{Ag}^{+}$, representing a low value for electro-reduction of carbon dioxide in an organic electrolyte. A current density of 65.8 $\mathrm{mA} \cdot \mathrm{cm}^{-2}$ at $-1.8 \mathrm{~V}$ vs. $\mathrm{Ag} / \mathrm{Ag}^{+}$is observed with a Faradaic efficiency to formic acid of 90.5\%. Electron paramagnetic resonance spectroscopy confirms that the templated electrosynthesis affords structural defects in the metal-organic framework film comprising uncoupled $\mathrm{Cu}(\mathrm{II})$ centres homogenously distributed throughout. These active sites promote catalytic performance as confirmed by computational modelling.

\footnotetext{
${ }^{1}$ Department of Chemistry, University of Manchester, Manchester M13 9PL, UK. ${ }^{2}$ Beijing National Laboratory for Molecular Sciences, CAS Key Laboratory of Colloid, Interface and Chemical Thermodynamics, Institute of Chemistry, Chinese Academy of Science, 100190 Beijing, China. ${ }^{3}$ Photon Science Institute,

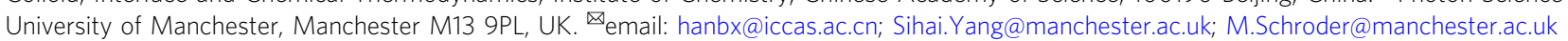


ncreasing $\mathrm{CO}_{2}$ levels in the atmosphere present significant environmental impacts ${ }^{1-3}$. Thus, routes to carbon capture and storage, as well as development of $\mathrm{CO}_{2}$ reduction technologies to afford chemical feedstocks are being developed ${ }^{4-6}$. Reduction of $\mathrm{CO}_{2}$ is economically and environmentally desirable but technically challenging because the high energy of the $\mathrm{C}=\mathrm{O}$ bond $(750$ $\mathrm{kJ} \cdot \mathrm{mol}^{-1}$ ) makes it an extremely stable molecule that is reluctant to transform ${ }^{7-9}$. One effective method to overcome the high activation barrier is through electrochemical catalytic reduction in which $\mathrm{CO}_{2}$ is reduced under mild conditions ${ }^{10-13}$. Copper-based electrodes have been reported as powerful catalysts for the electroreduction of $\mathrm{CO}_{2}$ to give numerous products including $\mathrm{CO}$, formic acid and, recently, $\mathrm{C}_{2}$ and other products ${ }^{14-18}$. Formic acid is heavily used in chemical industries for leather, dyeing and textiles, and can be converted directly within fuel cells ${ }^{13,19}$, and is therefore a valuable $\mathrm{C}_{1}$ product. Reduction of $\mathrm{CO}_{2}$ at $\mathrm{Cu}$-based electrodes can proceed via O-bound $\mathrm{HCOO}-$ or $\mathrm{C}$-bound $-\mathrm{COOH}$ intermediates that are formed from electrochemically generated $\cdot \mathrm{CO}_{2}{ }^{-}$radicals. The latter route can diverge to other possible products ${ }^{20,21}$, but the electro-reduction of $\mathrm{CO}_{2}$ via an O-bound HCOO- pathway may enhance the Faradaic efficiency for the formation of formic acid. In addition, the formation of formic acid requires a highly negative potential for $\mathrm{CO}_{2}$ reduction, and this often leads to decomposition of copper-based catalyst via reduction of metal sites during electrolysis. Although emerging electrocatalysts have been reported for reduction of $\mathrm{CO}_{2}$ to formic acid at low over-potentials ${ }^{17}$, more work needs to be undertaken to understand the details of this catalysis ${ }^{22,23}$.

In recent years, there has been much interest in metal-organic framework (MOF) materials as crystalline porous hosts for gas adsorption, separation and catalysis ${ }^{24-26}$. Their high surface area, potentially active metal centres, diverse pore structure and, in exceptional cases, their redox activity, promote their use as electrocatalysts for $\mathrm{H}_{2}$ and $\mathrm{O}_{2}$ evolution and reduction of $\mathrm{O}_{2}{ }^{27-29}$. However, highly crystalline MOFs with fully coordinated metal centres exhibit only low charge-transfer ability and formally no active centres for electrocatalysis ${ }^{12}$. Therefore, in order to drive efficient electrocatalysis, MOFs that exhibit high capacity for charge-transfer and incorporate accessible metal sites are highly desirable.

Herein, we report the templated electrochemical growth of the $\mathrm{Cu}(\mathrm{II})$ complex $\left[\mathrm{Cu}_{2}(\mathrm{~L})\right] \quad\left[\mathrm{H}_{4} \mathrm{~L}=4,4^{\prime}, 4^{\prime \prime}, 4^{\prime \prime \prime}\right.$-(1,4-phenylenebis (pyridine-4,2,6-triyl))tetrabenzoic acid] (Supplementary Fig. 1) on a $\mathrm{Cu}$-foam electrode to introduce abundant structural defects comprised of active $\mathrm{Cu}(\mathrm{II})$ sites within the deposited film. The resultant electrode, $\mathrm{Cu}_{2}(\mathrm{~L})-\mathrm{e} / \mathrm{Cu}$, shows excellent activity for the reduction of $\mathrm{CO}_{2}$ to formic acid with an onset potential of -1.45 $\mathrm{V}$ vs. $\mathrm{Ag} / \mathrm{Ag}^{+}$for production of formic acid, a Faradaic efficiency $\left(\mathrm{FE}_{\mathrm{HCOOH}}\right)$ reaching $90.5 \%$ at $-1.8 \mathrm{~V}$ vs. $\mathrm{Ag} / \mathrm{Ag}^{+}$and a current density of $65.8 \mathrm{~mA} \cdot \mathrm{cm}^{-2}$. Side reactions, such as $\mathrm{H}_{2}$ evolution and reduction of $\mathrm{Cu}(\mathrm{II})$ sites, are effectively hindered at low potentials, and the catalytic mechanism has been studied by electron paramagnetic resonance (EPR) spectroscopy and density functional theory (DFT) calculations.

\section{Results and discussion}

Electrosynthesis of $\mathbf{C u}_{2}(\mathbf{L})-\mathbf{e} / \mathbf{C u}$. The ligand $\mathrm{H}_{4} \mathrm{~L}$ was synthesised via a three-step method from our previous report ${ }^{30}$. The electrode, $\mathrm{Cu}_{2}(\mathrm{~L})-\mathrm{e} / \mathrm{Cu}$, was prepared by electro-synthesis of the $\mathrm{MOF}$ on $\mathrm{Cu}$-foam at a potential of $8.0 \mathrm{~V}$ at $60^{\circ} \mathrm{C}$ in the presence of the ionic liquid 1-ethyl-3-methylimidazolium acetate (EmimOAc, Supplementary Fig. 2) as supporting electrolyte (Supplementary Fig. 3). Upon completion, the porous $\mathrm{Cu}$-foam was uniformly coated with green crystallites of $\mathrm{Cu}_{2}(\mathrm{~L})$-e (Fig. 1a-d) thus limiting the further supply of $\mathrm{Cu}^{2+}$ ions from the anode for synthesis of more MOF material. SEM images confirm the spherical morphology of the complex film with an average particle size of $\sim 50 \mathrm{~nm}$ (Fig. 1e, f). For comparison, the MOF was also synthesised by a conventional solvothermal reaction [denoted as $\left.\mathrm{Cu}_{2}(\mathrm{~L})-\mathrm{t}\right]^{31}$, which crystallised in much larger octahedralshaped crystals of several microns in size (Supplementary Fig. 4). The structure of $\mathrm{Cu}_{2}(\mathrm{~L})$ comprises of a $3 \mathrm{D}$ network built around binuclear $\left[\mathrm{Cu}_{2}(\mathrm{OOCR})_{4}\right]$ paddlewheels with four bridging carboxylate ligands (Fig. 1g, h) ${ }^{32}$.

Structural analysis and characterisation of $\mathrm{Cu}_{2}(\mathrm{~L})$. Power X-ray diffraction (PXRD) confirmed that $\mathrm{Cu}_{2}(\mathrm{~L})-\mathrm{t}$ and $\mathrm{Cu}_{2}(\mathrm{~L})-\mathrm{e}$ (removed from the electrode) have the same structure consistent with the simulated pattern (Fig. $2 \mathrm{a})^{31}$. We sought to characterise the nature of the structural defects in $\mathrm{Cu}_{2}(\mathrm{~L})$-e, which can be captured vividly by confocal fluorescence microscopy (CFM) using the oligomerisation of furfuryl alcohol as a probe ${ }^{33}$. In this case, open $\mathrm{Cu}(\mathrm{II})$-site based defects act as Lewis acid centres that catalyse the formation of oligomers of furfuryl alcohol to generate strong fluorescence. The microphotographs and CFM images show (Fig. 2b, c) fluorescence evenly across particles of $\mathrm{Cu}_{2}(\mathrm{~L})$-e, whereas only the surfaces of $\mathrm{Cu}_{2}(\mathrm{~L})$ - $\mathrm{t}$ exhibit fluorescence, confirming the wide distribution of open $\mathrm{Cu}(\mathrm{II})$ defect sites throughout $\mathrm{Cu}_{2}(\mathrm{~L})$-e. Fourier transform infrared (FTIR) spectroscopy shows that the $v(\mathrm{C}=\mathrm{O})$ stretching vibration of the carboxylate group in $\mathrm{Cu}_{2}(\mathrm{~L})$-e is blue shifted by $17 \mathrm{~cm}^{-1}$, from 1385 $\mathrm{cm}^{-1}$ to $1402 \mathrm{~cm}^{-1}$, compared to $\mathrm{Cu}_{2}(\mathrm{~L})-\mathrm{t}$, consistent with increased amounts of unbound carboxylate groups in the former (Fig. 2d). A slight decrease in decomposition temperature for $\mathrm{Cu}_{2}(\mathrm{~L})$-e compared to $\mathrm{Cu}_{2}(\mathrm{~L})$-t by TGA analysis suggests that the defect structure of $\mathrm{Cu}_{2}(\mathrm{~L})$-e has slightly reduced thermal stability (Fig. 2e). Full elemental analysis of these materials reveals a $\mathrm{Cu}: \mathrm{L}$ ratio of 2.4 in $\mathrm{Cu}_{2}(\mathrm{~L})$-e (Supplementary Table 1), higher than the 2.0 ratio obtained for $\mathrm{Cu}_{2}(\mathrm{~L})-\mathrm{t}$. This reflects the direct growth of $\mathrm{Cu}_{2}(\mathrm{~L})$-e onto the $\mathrm{Cu}$-foam surface to give a more $\mathrm{Cu}$-rich environment. X-band and Q-band EPR spectra at room temperature reveal a significantly greater concentration of uncoupled $\mathrm{Cu}$ (II) defect sites in $\mathrm{Cu}_{2}(\mathrm{~L})$-e than in $\mathrm{Cu}_{2}(\mathrm{~L})$-t (Fig. 2f, g, Supplementary Figs. 5-8). The spectra are dominated by the characteristic spin triplet spectrum of the $\left[\mathrm{Cu}_{2}(\mathrm{OOCR})_{4}\right]$ paddlewheel structure, which arise from strong antiferromagnetic exchange (singlet-triplet gap ca. $300 \mathrm{~cm}^{-1}$ ) within the binuclear moiety and the thermal population of the excited $S=1$ state, which has a zero-field splitting of $c a .0 .3 \mathrm{~cm}^{-1}$. The characteristic forbidden transition $\left(m_{\mathrm{S}}= \pm 2\right)$ associated with the triplet spin state of the $\mathrm{Cu}_{2}$ entity is clearly observed $(\mathrm{ca} .5300 \mathrm{G})$ in all Q-band spectra of $\mathrm{Cu}_{2}(\mathrm{~L})-\mathrm{e}$ and $\mathrm{Cu}_{2}(\mathrm{~L})-\mathrm{t}$ (Fig. $2 \mathrm{~g}$ and Supplementary Fig. 8). In addition, features due to uncoupled $\mathrm{Cu}(\mathrm{II})\left(S=1 / 2, g_{\mathrm{xx}, \mathrm{yy}}=2.07\right.$, $g_{\mathrm{zz}}=2.32, A_{\mathrm{xx}, \mathrm{yy}} \mathrm{Cu}=33.6 \mathrm{MHz}$, and $\left.A_{\mathrm{zz}} \mathrm{Cu}=450 \mathrm{MHz}\right)$ ions are observed (ca. 3250G at X-band; $12000 \mathrm{G}$ at Q-band), and these signals are more pronounced in $\mathrm{Cu}_{2}(\mathrm{~L})$-e than in $\mathrm{Cu}_{2}(\mathrm{~L})-\mathrm{t}$ (Fig. 2f, g). The relative concentration of $\left[\mathrm{Cu}_{2}(\mathrm{OOCR})_{4}\right]$ paddlewheel units and uncoupled free $\mathrm{Cu}(\mathrm{II})$ is given by the relative intensity of the second integral of simulations of the Q-band EPR spectra, weighted by the room temperature Boltzmann population of the spin triplet state of the $\left[\mathrm{Cu}_{2}(\mathrm{OOCR})_{4}\right]$ paddlewheel (Fig. 2h, i and Supplementary Table 2$)^{34-36}$. Using this approach it was determined that $\mathrm{Cu}_{2}(\mathrm{~L})-\mathrm{t}$ and $\mathrm{Cu}_{2}(\mathrm{~L})$-e contain $1.5 \%$ and $15.3 \%$ of uncoupled $\mathrm{Cu}(\mathrm{II})$ sites, respectively, confirming that electro-synthesis generates an order of magnitude greater number of defect sites.

Analysis of porosity in $\mathbf{C u}_{\mathbf{2}}(\mathrm{L})$. The porosity of these MOFs was studied by $\mathrm{N}_{2}$ isotherms at $77 \mathrm{~K}$ (Fig. $2 \mathrm{j}$ and Supplementary Table 1). Desolvated $\mathrm{Cu}_{2}(\mathrm{~L})$-t shows a Type-I sorption profile 

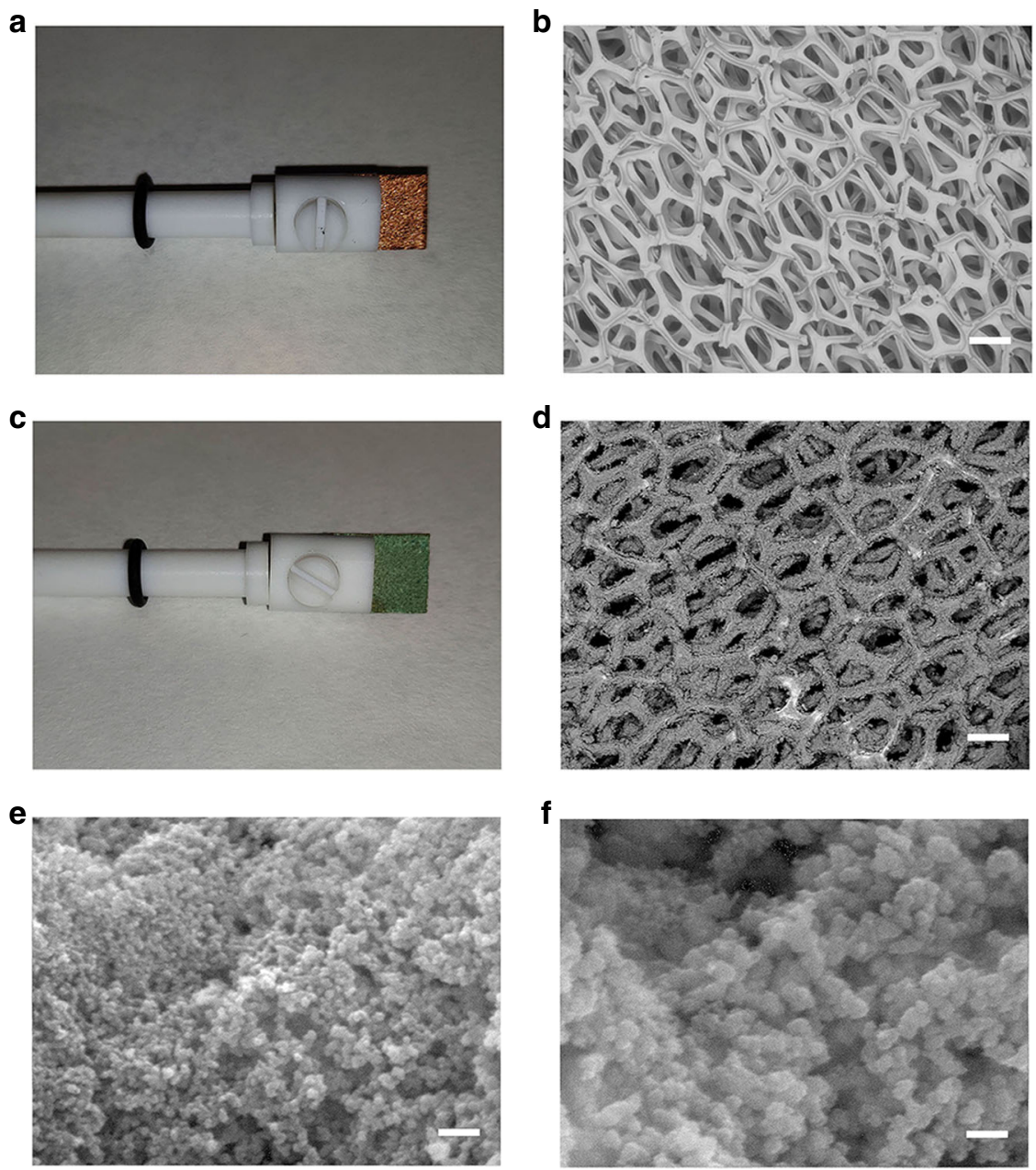

g

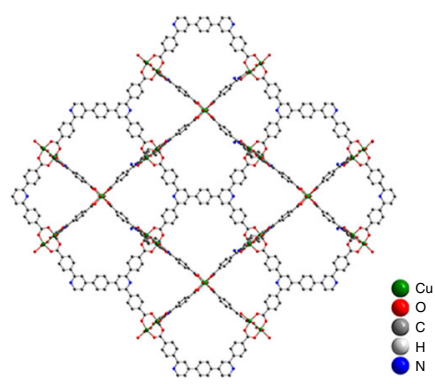

h

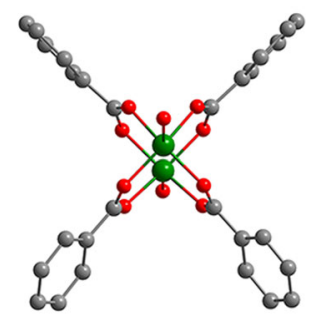

Fig. 1 Images and morphology. a, b Photograph (a) and SEM image (b) of a fresh Cu-foam electrode $\left(0.5 \times 1.0 \mathrm{~cm}^{2}\right)$. c Photograph of the as-prepared electrode $\mathrm{Cu}_{2}(\mathrm{~L})$-e/Cu $\left(0.5 \times 1.0 \mathrm{~cm}^{2}\right)$. d-f SEM images of the as-prepared electrode $\mathrm{Cu}_{2}(\mathrm{~L})$-e/Cu. $\mathbf{g}-\mathbf{h}$ Views of the crystal structure of $\left[C u_{2}(\mathrm{~L})\right](\mathrm{CCDC}$ 1531622) ${ }^{31}$. Hydrogen atoms are omitted for clarity. The scale bars of $\mathbf{b}, \mathbf{d}-\mathbf{f}$ are $300 \mu \mathrm{m}, 300 \mu \mathrm{m}, 300 \mathrm{~nm}$ and $100 \mathrm{~nm}$, respectively.

consistent with the expected uniform microporosity. In contrast, desolvated $\mathrm{Cu}_{2}(\mathrm{~L})$-e exhibits a profile between Type-I and Type-IV, suggesting the presence of both mesopores and micropores. The distribution of micro- and mesopores within both materials has been analysed by Horvath-Kawazoe and Barrett-Joyner-Halenda (BJH) methods, respectively (Fig. 2k, l). The reduction in micropores in $\mathrm{Cu}_{2}(\mathrm{~L})$-e results in a low $\mathrm{N}_{2}$ uptake at low pressure, while $\mathrm{Cu}_{2}(\mathrm{~L})$-e, generated by the template-effect of the ionic liquid during electro-synthesis ${ }^{33}$, shows a total pore volume of $1.89 \mathrm{~cm}^{3} \cdot \mathrm{g}^{-1}$, significantly larger than that of $\mathrm{Cu}_{2}(\mathrm{~L})-\mathrm{t}\left(0.32 \mathrm{~cm}^{3} \cdot \mathrm{g}^{-1}\right)$, reflecting the presence of mesopores in $\mathrm{Cu}_{2}(\mathrm{~L})$-e. $\mathrm{CO}_{2}$ adsorption in desolvated $\mathrm{Cu}_{2}(\mathrm{~L})$ - $\mathrm{t}$ and $\mathrm{Cu}_{2}(\mathrm{~L})$-e at 1.0 bar and $298 \mathrm{~K}$ are 38.5 and $44.7 \mathrm{~cm}^{3} \mathrm{~g}^{-1}$, respectively (Fig. $2 \mathrm{~m}$ ). Higher isosteric heats of adsorption $\left(Q_{s t}\right)$ were obtained for $\mathrm{Cu}_{2}(\mathrm{~L})$-e (Supplementary Figs. 9, 10), suggesting stronger interactions with $\mathrm{CO}_{2}$ than in $\mathrm{Cu}_{2}(\mathrm{~L})$ - $\mathrm{t}$, consistent with the presence of additional active sites in the former. In summary, electro-synthesised $\mathrm{Cu}_{2}(\mathrm{~L})$-e can be grown directly onto $\mathrm{Cu}$-foam to afford a decorated electrode incorporating a defect structure with active $\mathrm{Cu}(\mathrm{II})$ sites that show strong interaction with $\mathrm{CO}_{2}$, a key feature for an optimal catalyst for $\mathrm{CO}_{2}$ reduction ${ }^{37}$. For comparison, the benchmark system HKUST-1 has also been electro-synthesised onto $\mathrm{Cu}$-foam (denoted as HKUST-1-e/Cu) using the same method, and fully characterised by SEM, PXRD, TGA and BET (Supplementary Figs. 11-14 and Supplementary Table 1). High crystallinity and large particle sizes $(\sim 1 \mu \mathrm{m})$ were obtained for HKUST-1-e, consistent with its facile crystal growth. 
a
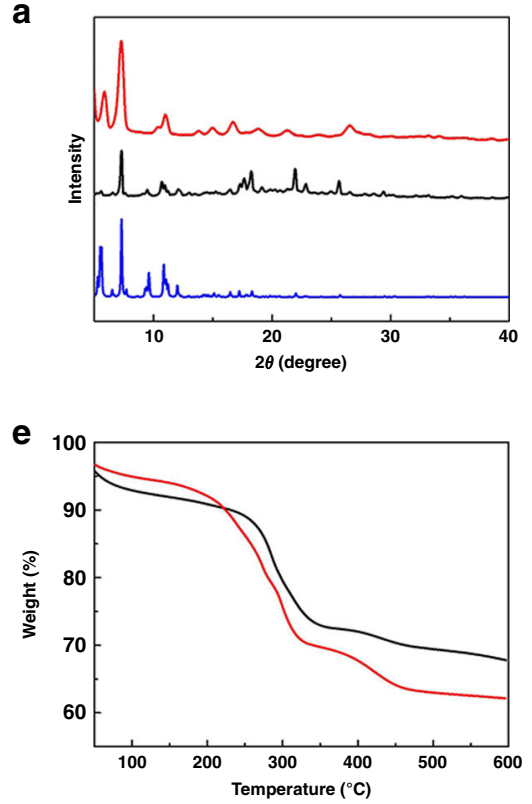

h
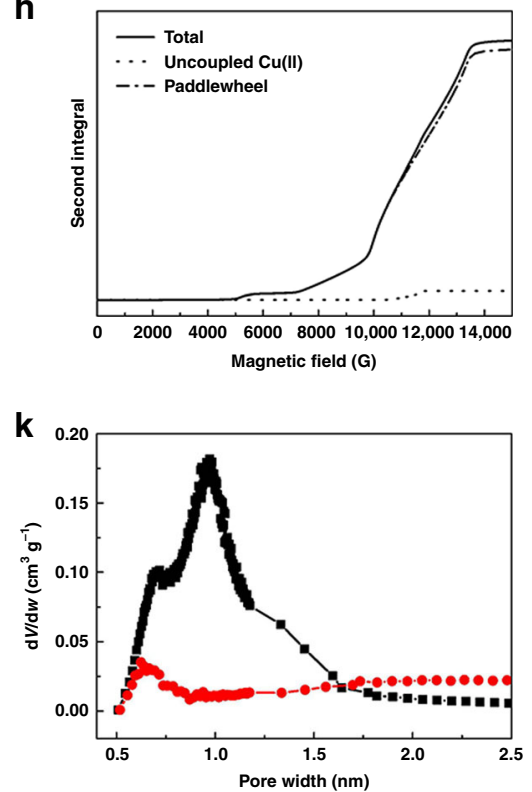

b

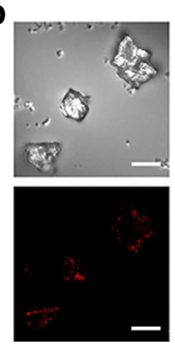

c

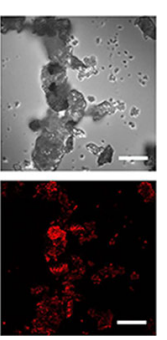

f

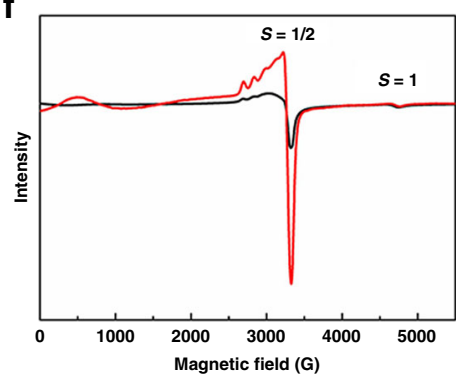

i

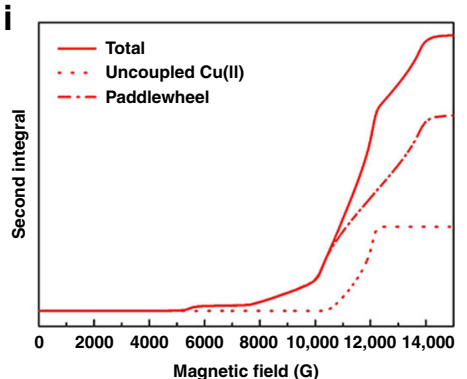

I

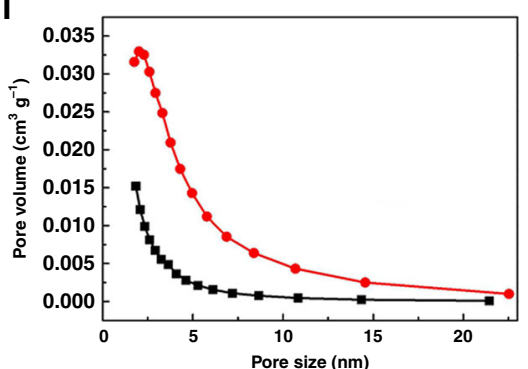

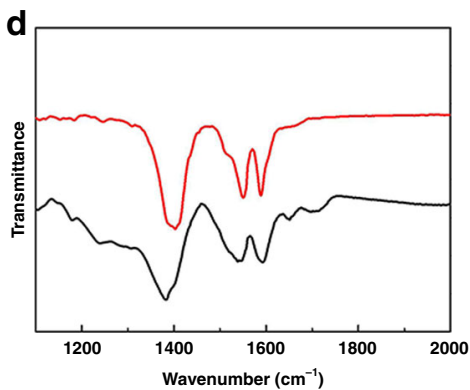
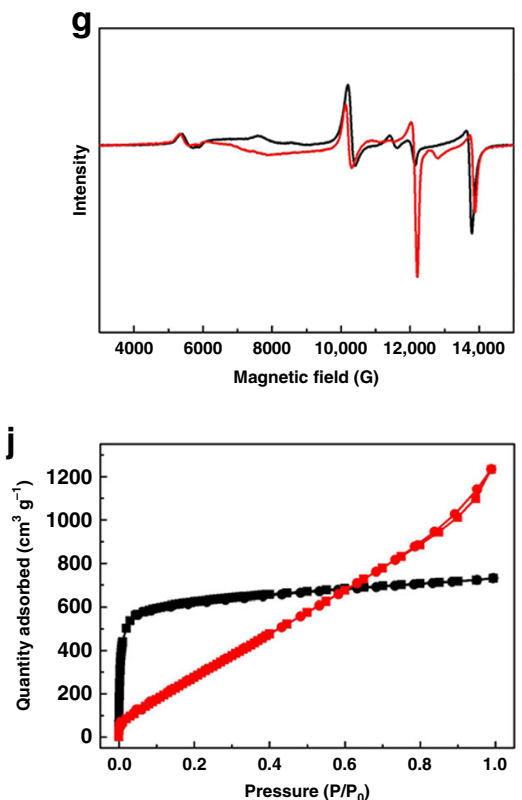

m

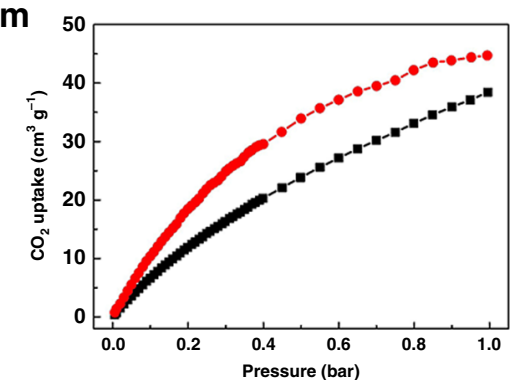

Fig. $\mathbf{2}$ Characterisations of $\mathbf{C u}_{\mathbf{2}}(\mathbf{L})$-t (black lines) and $\mathbf{C u}_{\mathbf{2}}(\mathbf{L})$-e (red lines). a PXRD patterns (blue line refers to simulated PXRD pattern). The defects in $\mathrm{Cu}_{2}(\mathrm{~L})$-e result in broadening of peaks due to poorer crystallinity of the material. $\mathbf{b}$ Micrograph (top) and $\mathrm{CFM}$ image (bottom) of $\mathrm{Cu}_{2}(\mathrm{~L})$-t. The fluorescence (shown in red colour) indicates the presence of crystal defects determined by the oligomerisation of furfuryl alcohol. c Micrograph (top) and CFM image (bottom) of $\mathrm{Cu}_{2}(\mathrm{~L})$-e. $\mathbf{d}$ Selected FTIR spectra (full spectra are shown in Supplementary Information). e TGA curves. $\mathbf{f} X$-band EPR spectra at room temperature. $\mathbf{g}$ Q-band EPR spectra at room temperature. $\mathbf{h}$ Second integrals from simulated Q-band EPR spectra for $\mathrm{Cu}_{2}(\mathrm{~L})$-t. i Second integrals from simulated Q-band EPR spectra for $\mathrm{Cu}_{2}(\mathrm{~L})$-e. $\mathbf{j} \mathrm{N}_{2}$ adsorption/desorption isotherms at $77 \mathrm{~K}$. $\mathbf{k}$ Micropore size distribution. I Mesopore size distribution. m Adsorption isotherms for $\mathrm{CO}_{2}$ at $298 \mathrm{~K}$ (desorption data are shown in Supplementary Information). Data for HKUST-1-e are shown in Supplementary Information. The scale bars of $\mathbf{b}$ and $\mathbf{c}$ are $20 \mu \mathrm{m}$.

Electrochemical reduction of $\mathrm{CO}_{2}$. To test performance for electrochemical reduction of $\mathrm{CO}_{2}, \mathrm{Cu}_{2}(\mathrm{~L})$-e/Cu and HKUST-1-e/ $\mathrm{Cu}$ were used directly as electrodes, while a powder sample of $\mathrm{Cu}_{2}(\mathrm{~L})$-t was loaded onto carbon paper (CP) with Nafion-D521 as adhesive to fabricate a $\mathrm{Cu}_{2}(\mathrm{~L})-\mathrm{t} / \mathrm{CP}$ electrode ${ }^{12}$. All experiments were performed in an $\mathrm{H}$-type cell with $0.5 \mathrm{M}$ 1-ethyl-3methylimidazolium tetrafluoroborate $\left(\mathrm{EmimBF}_{4}\right)$ in acetonitrile $\left(0.5 \mathrm{M} \mathrm{EmimBF}_{4} / \mathrm{MeCN}\right)$ as catholyte. As shown from the linear sweep voltammetry at the $\mathrm{Cu}_{2}(\mathrm{~L})$-e/Cu electrode, negligible current was generated in $\mathrm{N}_{2}$-saturated electrolyte, while the current density increased dramatically in $\mathrm{CO}_{2}$-saturated electrolyte, confirming a strong response to $\mathrm{CO}_{2}$ (Supplementary Fig. 15). The dependence of current density on time ( $i$ - $t$ curves) for all three electrodes is shown in Fig. 3a. Minimal current density was observed with $\mathrm{N}_{2}$, whereas a rise in current density is observed on introduction of $\mathrm{CO}_{2}$. The current density continuously increases in the presence of $\mathrm{CO}_{2}$ and stabilises after $1 \mathrm{~h}$ for the three electrodes. The $\mathrm{Cu}_{2}(\mathrm{~L})$-e/Cu electrode shows the highest current density, and for all systems, formic acid was found to be the only carbon-containing product based on GC and ${ }^{1} \mathrm{H}$ NMR 

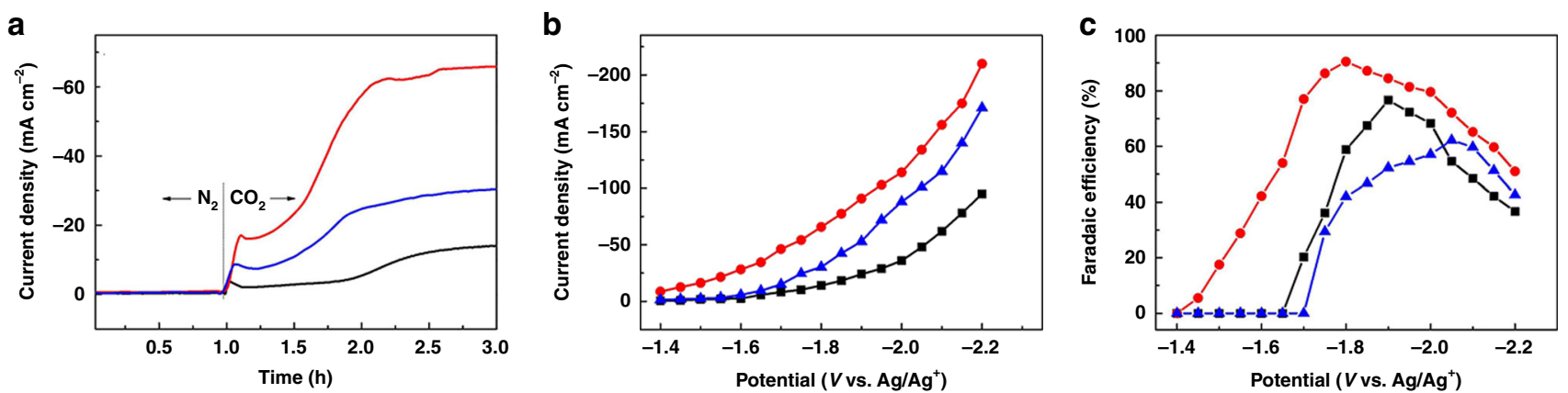

Fig. 3 Electrochemical reduction of $\mathrm{CO}_{2}$ over $\mathrm{Cu}_{2}(\mathrm{~L})-\mathrm{t} / \mathrm{CP}$ (black lines), $\mathrm{Cu}_{2}(\mathrm{~L})-\mathrm{e} / \mathrm{Cu}$ (red lines), and $\mathrm{HKUST-1-e/Cu}$ (blue lines). a Plot of current density vs. time. $\mathbf{b}$ Plot of current density vs. potential. c Plot of $\mathrm{FE}_{\mathrm{HCOOH}}$ vs. potential.

spectroscopic analysis of gas and liquid phases, respectively, after electrolysis. No carbon-containing product was detected in the absence of $\mathrm{CO}_{2}$ from the catholyte, confirming that the generated formic acid is derived solely from introduced $\mathrm{CO}_{2}$ rather than decomposition of the catalyst or electrolyte. The current density and Faradaic efficiency for formation of formic acid ( $\left.\mathrm{FE}_{\mathrm{HCOOH}}\right)$ were recorded after $2 \mathrm{~h}$ of electrolysis (Fig. $3 \mathrm{~b}, \mathrm{c}$ ) from $-1.4 \mathrm{~V}$ to $-2.2 \mathrm{~V}$ vs. $\mathrm{Ag} / \mathrm{Ag}^{+} . \mathrm{H}_{2}$ is the only bi-product within this potential range. Significantly, the $\mathrm{Cu}_{2}(\mathrm{~L})$-e/Cu electrode shows an onset potential of $-1.45 \mathrm{~V}$ vs. $\mathrm{Ag} / \mathrm{Ag}^{+}$for the generation of formic acid, representing one of the lowest potential observed in organic electrolytes for systems reported to date (Supplementary Table 3$)^{6,38-40}$, although a recent $\mathrm{Cu}$-porphyrin system shows an onset voltage as low as $-1.4 \mathrm{~V}$ vs. $\mathrm{Ag} / \mathrm{Ag}^{+} .17$ The current density increases with increasing negative potential, but $\mathrm{FE}_{\mathrm{HCOOH}}$ increases and then decreases, reaching a maximum of $90.5 \%$ at $-1.8 \mathrm{~V}$ vs. $\mathrm{Ag} / \mathrm{Ag}^{+}$with a current density of $65.8 \mathrm{~mA} \cdot \mathrm{cm}^{-2}$. The value of $\mathrm{FE}_{\mathrm{HCOOH}}$ is maintained at $>80 \%$ between $-1.75 \mathrm{~V}$ to $-1.95 \mathrm{~V}$ vs. $\mathrm{Ag} / \mathrm{Ag}^{+}$. In comparison, the $\mathrm{Cu}_{2}(\mathrm{~L})-\mathrm{t} / \mathrm{CP}$ electrode exhibits a higher onset potential of $-1.7 \mathrm{~V}$ vs. $\mathrm{Ag} / \mathrm{Ag}^{+}$for formic acid production and a lower current density across the potential range, with a maximum $\mathrm{FE}_{\mathrm{HCOOH}}$ of $77 \%$ observed at $-1.9 \mathrm{~V}$ vs. $\mathrm{Ag} / \mathrm{Ag}^{+}$. For the HKUST-1-e/Cu electrode, an even higher onset potential of $-1.75 \mathrm{~V}$ vs. $\mathrm{Ag} / \mathrm{Ag}^{+}$was observed for production of formic acid, and $\mathrm{FE}_{\mathrm{HCOOH}}$ reaches a maximum of $62 \%$ at -2.05 vs. $\mathrm{Ag} / \mathrm{Ag}^{+}$. Thus, $\mathrm{Cu}_{2}(\mathrm{~L})-\mathrm{e} / \mathrm{Cu}$ demonstrates an excellent performance for electro-reduction of $\mathrm{CO}_{2}$ in terms of the low onset potential and high $\mathrm{FE}_{\mathrm{HCOOH}}$ with relatively low over-potentials. The current density for formic acid production increases rapidly from the onset potential to $-2.0 \mathrm{~V}$ vs. $\mathrm{Ag} / \mathrm{Ag}^{+}$, and the production of formic acid progresses slowly thereafter (Supplementary Fig. 16), reflecting the enhanced production of $\mathrm{H}_{2}$ at potentials more negative than $-2.0 \mathrm{~V}$ vs. $\mathrm{Ag} / \mathrm{Ag}^{+}$. At potentials more negative than $-2.0 \mathrm{~V}$ vs. $\mathrm{Ag} / \mathrm{Ag}^{+}$, the HKUST-1-e/Cu electrode shows a rise in current density (Fig. 3b) with the current density of formic acid reaching a plateau (Supplementary Fig. 16). An undecorated $\mathrm{Cu}$-foam electrode (Fig. 1a, b) was also tested, and a current density of $4.2 \mathrm{~mA} \cdot \mathrm{cm}^{-2}$ with a $\mathrm{FE}_{\mathrm{HCOOH}}$ of $20.5 \%$ after $2 \mathrm{~h}$ electrolysis at $-1.8 \mathrm{~V}$ vs. $\mathrm{Ag} / \mathrm{Ag}^{+}$were observed (Supplementary Fig. 17), demonstrating the critical role of defect $\mathrm{Cu}_{2}(\mathrm{~L})$ on the performance of the electrode. It should be noted that a nanostructured $\mathrm{Cu}$-foam has been explored previously as an electrocatalyst ${ }^{16}$; the $\mathrm{Cu}$-foam in the current study is of a different type and is much smoother.

Upon completion of reaction, HKUST-1-e turned amorphous and partially peeled off the $\mathrm{Cu}$-foam as confirmed by SEM images. In contrast, $\mathrm{Cu}_{2}(\mathrm{~L})$-e/Cu generally maintained its morphology with a slight aggregation of particles (Supplementary Fig. 18). Thus, the thin coating with small crystallites in the $\mathrm{Cu}_{2}(\mathrm{~L})-\mathrm{e} / \mathrm{Cu}$ electrode affords chemical and mechanical stability for electrolysis, although like many $\mathrm{Cu}(\mathrm{II}) \mathrm{MOFs}^{15}$, the $\mathrm{Cu}_{2}(\mathrm{~L})-\mathrm{e} /$ $\mathrm{Cu}$ electrode is unstable in water.

Variations of EPR spectra of electrodes over time. To understand further the mechanism of catalysis of these electrodes, EPR spectra were measured over time intervals of 15 mins during electrolysis of $\mathrm{CO}_{2}$ at $-1.8 \mathrm{~V}$ vs. $\mathrm{Ag} / \mathrm{Ag}^{+}$. We sought to use EPR spectroscopy to probe changes in concentrations of free, uncoupled $\mathrm{Cu}(\mathrm{II})$ centres as the reaction proceeds ${ }^{41}$, and this can be monitored by the relative intensity of the second integral of the EPR spectrum (Fig. 4a). As confirmed above, as-prepared $\mathrm{Cu}_{2}(\mathrm{~L})$ e/ $\mathrm{Cu}$ has a high concentration of uncoupled $\mathrm{Cu}$ (II) centres due to its defect structure. All three electrodes show an increase in uncoupled $\mathrm{Cu}(\mathrm{II})$ content during electrolysis: this is presumably caused by reduction of the $\left[\mathrm{Cu}_{2}(\mathrm{OOCR})_{4}\right]$ paddlewheel units under the electrolytic conditions, with subsequent structural disruption. The amount of free $\mathrm{Cu}(\mathrm{II})$ sites was maximised after electrolysis for 75,60 and 45 mins for $\mathrm{Cu}_{2}(\mathrm{~L})-\mathrm{e} / \mathrm{Cu}, \mathrm{Cu}_{2}(\mathrm{~L})-\mathrm{t} / \mathrm{CP}$ and HKUST-1-e/Cu, respectively, followed by a slight decrease for $\mathrm{Cu}_{2}(\mathrm{~L})-\mathrm{e} / \mathrm{Cu}$ and a greater decrease in $\mathrm{Cu}_{2}(\mathrm{~L})-\mathrm{t} / \mathrm{CP}$ and HKUST-1-e/Cu. The quantities of uncoupled $\mathrm{Cu}(\mathrm{II})$ sites decrease after a maximum and are likely due to reduction to diamagnetic $\left(3 \mathrm{~d}^{10}\right) \mathrm{Cu}(\mathrm{I})$ over time (Supplementary Fig. 19), as confirmed by XPS and Auger spectra (Supplementary Fig. 20). These results also support the thesis that free $\mathrm{Cu}$ (II) defect sites are responsible for the high current density and $\mathrm{FE}_{\mathrm{HCOOH}}$ observed for $\mathrm{Cu}_{2}(\mathrm{~L})$-e/Cu throughout the electrolysis of $\mathrm{CO}_{2}$ (Fig. 4b, c) $\mathrm{H}_{2}$ evolution becomes more evident over time using $\mathrm{Cu}_{2}(\mathrm{~L})-\mathrm{t} / \mathrm{CP}$ and HKUST-1-e/Cu electrodes also likely due to generation of $\mathrm{Cu}(\mathrm{I})$ sites over time (Supplementary Fig. 21). The reduction of $\left[\mathrm{Cu}_{2}(\mathrm{OOCR})_{4}\right]$ paddlewheel MOFs to form $\mathrm{Cu}(\mathrm{II})$. $\mathrm{Cu}(\mathrm{I})$ species has been reported previously ${ }^{42}$, and is associated with tetrahedral distortion of the reduced metal centre to give an uncoupled $\mathrm{Cu}$ (II) centre. The current density for formation of formic acid remains constant after the uncoupled $\mathrm{Cu}$ (II) content reaches its maximum value, and so catalysis remains stable up to $5 \mathrm{~h}$ (Supplementary Figs. 22, 23). Thus, $\mathrm{Cu}_{2}(\mathrm{~L})$-e/Cu exhibits the best performance for long-term electrochemical stability for formic acid production. It is notable that the total Faradaic efficiency for formation of formic acid and $\mathrm{H}_{2}\left(\mathrm{FE}_{\mathrm{HCOOH}+\mathrm{H} 2}\right)$ is lower than $100 \%$ during the first hour of electrolysis (Supplementary Fig. 24), indicating that the electrode evolves during this early period of electrolysis, consistent with the morphological changes observed at the electrode surface (Supplementary Fig. 18).

Electrochemical characteristics of electrodes. The chargetransfer ability of the electrode also plays an important role in its electrocatalytic performance. As revealed by Nyquist plots at an open circuit potential (Fig. $4 \mathrm{~d}$ ), the $\mathrm{Cu}_{2}(\mathrm{~L})-\mathrm{e} / \mathrm{Cu}, \mathrm{Cu}_{2}(\mathrm{~L})-\mathrm{t} / \mathrm{CP}$ 
a

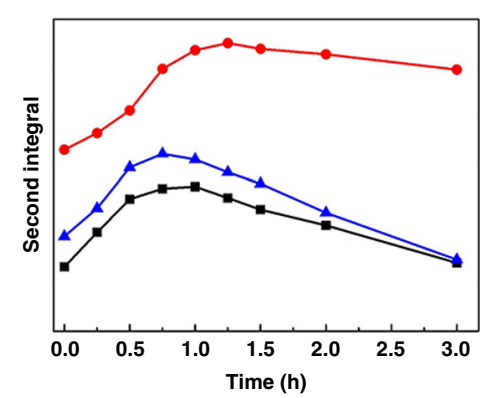

d

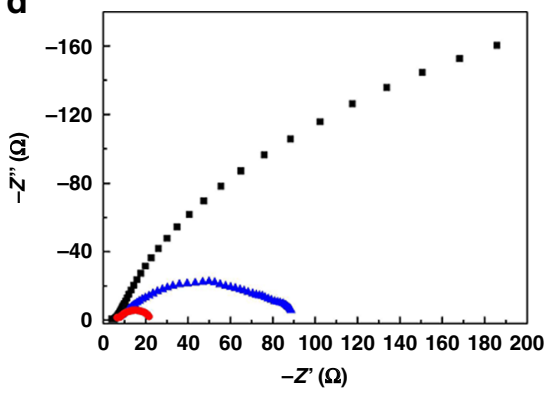

b

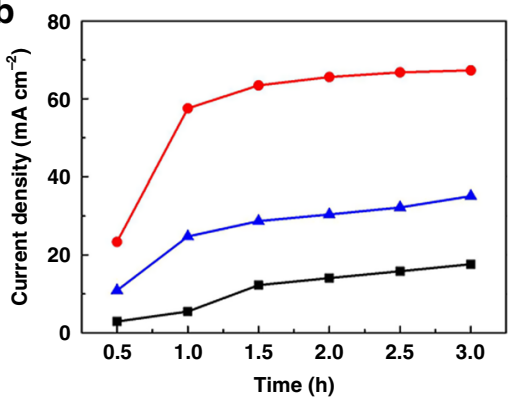

e

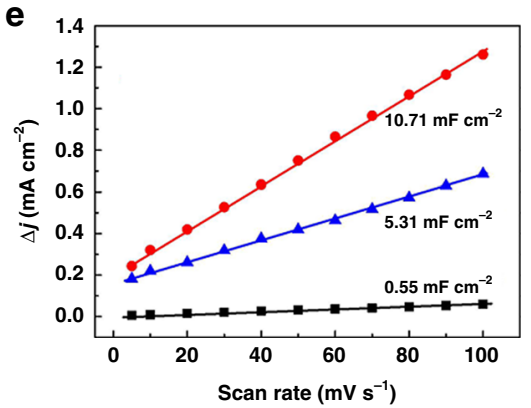

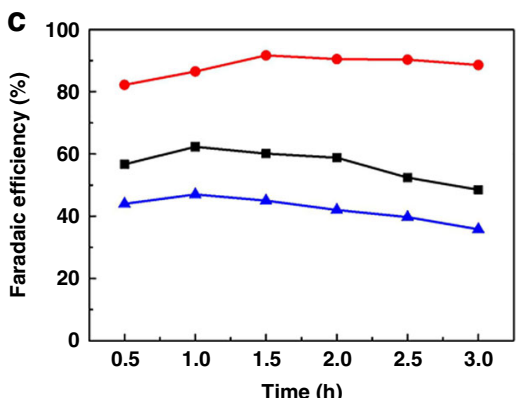

f

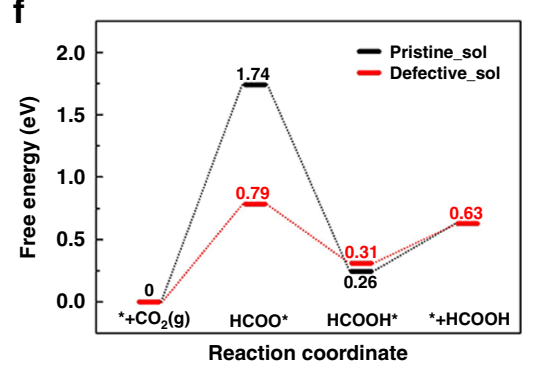

Fig. 4 Comparisons of $\mathbf{C u}_{\mathbf{2}}(\mathrm{L})-\mathrm{t} / \mathrm{CP}$ (black lines), $\mathbf{C u}_{\mathbf{2}}(\mathrm{L})-\mathrm{e} / \mathrm{Cu}$ (red lines) and HKUST-1-e/Cu (blue lines). a, Plot of second integral of the X-band EPR signals for uncoupled $\mathrm{Cu}(\mathrm{II})$ centres at room temperature vs. time of $\mathrm{CO}_{2}$ electrolysis. b Plot of current density vs. time of $\mathrm{CO}_{2}$ electrolysis at $-1.8 \mathrm{~V}$ vs. $\mathrm{Ag} / \mathrm{Ag}^{+}$. c Plot of $\mathrm{FE}_{\mathrm{HCOOH}}$ vs. time of $\mathrm{CO}_{2}$ electrolysis at $-1.8 \mathrm{~V} \mathrm{vs}$. $\mathrm{Ag} / \mathrm{Ag}^{+}$. $\mathbf{d}$ Nyquist plots for reduction of $\mathrm{CO}_{2}$. e Plot of difference in charging current density vs. scan rates. $\mathbf{f}$ DFT calculation of Gibbs free energy of electro-reduction of $\mathrm{CO}_{2}$ to formic acid over pristine (black lines) and defect $\mathrm{Cu}_{2}(\mathrm{~L})$ - $\mathrm{t}(\mathrm{red}$ lines) after consideration of solvation effects.

and HKUST-1-e/Cu electrodes give charge-transfer resistances $\left(\mathrm{R}_{\mathrm{ct}}\right)$ of approximately 17,114 and $408 \Omega$, respectively ${ }^{12,38}$. The significantly lower $\mathrm{R}_{\mathrm{ct}}$ for $\mathrm{Cu}_{2}(\mathrm{~L})-\mathrm{e} / \mathrm{Cu}$ is most likely due to its microscopic morphology as revealed from SEM images. Thus, nanoparticles of $\mathrm{Cu}_{2}(\mathrm{~L})$ form a compact thin coating on the $\mathrm{Cu}$ foam surface with the overall porous network preserved, whereas rapid crystallisation of HKUST-1 results in bigger crystals and a thick coating of HKUST-1-e/Cu, leading to a higher overall resistance. The poorly-conductive MOF islands on the HKUST-1e/Cu electrodes thus cause barriers for charge-transfer, in sharp contrast to $\mathrm{Cu}_{2}(\mathrm{~L})-\mathrm{e} / \mathrm{Cu}$, where all $\mathrm{MOF}$ particles are in close contact with the highly conductive $\mathrm{Cu}$-foam. The interface between $\mathrm{Cu}_{2}(\mathrm{~L})$ - $\mathrm{t}$ and $\mathrm{CP}$ results in the poor charge-transfer as observed in many other MOF-based electrodes ${ }^{12}$. The doublelayer capacitance $\left(C_{\mathrm{dl}}\right)$ of the three electrodes was analysed by measuring the capacitive current associated with double-layer charging using the scan-rate dependence of cyclic voltammetric stripping to evaluate the electrochemical active surface area (Fig. $4 \mathrm{e})^{43} \cdot \mathrm{Cu}_{2}(\mathrm{~L})-\mathrm{e} / \mathrm{Cu}$ has the highest value for $C_{\mathrm{dl}}$ of 10.71 $\mathrm{mF} \cdot \mathrm{cm}^{-2}$ with values for $\mathrm{Cu}_{2}(\mathrm{~L})-\mathrm{t} / \mathrm{CP}$ and HKUST-1-e/Cu of $5.31 \mathrm{mF} \cdot \mathrm{cm}^{-2}$ and $0.55 \mathrm{mF} \cdot \mathrm{cm}^{-2}$, respectively, again evidencing the high active surface area of $\mathrm{Cu}_{2}(\mathrm{~L})-\mathrm{e} / \mathrm{Cu}^{44,45}$.

DFT calculations. DFT calculations have been applied widely to uncover the mechanism of electro-reduction of $\mathrm{CO}_{2}{ }^{46-48}$. The Gibbs free energy with respect to potential reaction steps was modelled based upon a $\left[\mathrm{Cu}_{2}(\mathrm{OOCR})_{4}\right]$ paddlewheel bound to four 4-(pyridin-2-yl)benzoate groups. Pristine and defect structures representing $\mathrm{Cu}_{2}(\mathrm{~L})$ - $\mathrm{t}$ and $\mathrm{Cu}_{2}(\mathrm{~L})$-e, respectively, were then analysed by DFT calculations with defect $\mathrm{Cu}_{2}(\mathrm{~L})$ modelled with one of the O-donors of one 4-(pyridin-2-yl)benzoate not bound to $\mathrm{Cu}$ (II) to afford a vacant site at $\mathrm{Cu}(\mathrm{II})$. The corrections for zero point energy and entropy, and the structural model and atomic coordinates of all intermediates are given in Supplementary Tables 4-12. The plausible reaction pathways via C-bound
$\mathrm{COOH}$ and O-bound $\mathrm{HCOO}$ intermediates were analysed (Supplementary Figs. 25, 26) and the effects of solvation were also taken into account (Supplementary Fig. 27). In general, the formation of O-bound $\mathrm{HCOO}$ involved a lower Gibbs free energy than $\mathrm{C}$-bound $\mathrm{COOH}$ or $\mathrm{CO}$ over both pristine and defect $\mathrm{Cu}_{2}(\mathrm{~L})$, with formation of O-bound $\mathrm{HCOO}$ on defect $\mathrm{Cu}_{2}(\mathrm{~L})$ the most facile pathway leading to selective production of formic acid. In the DFT calculations the free $\mathrm{Cu}(\mathrm{II})$ centres in defect $\mathrm{Cu}_{2}(\mathrm{~L})$ are generated by the rupture of one $\mathrm{Cu}-\mathrm{O}$ (carboxylate) bond, which enables binding of $\mathrm{CO}_{2}$ via an O-bound $\mathrm{HCOO}$ intermediates. In addition, the defect structure leads to weaker hydrogen bonding between the MOF and product, facilitating the release of $\mathrm{HCOOH}$ from the surface of the $\mathrm{Cu}_{2}(\mathrm{~L})$-e/ $\mathrm{Cu}$ electrode. The same pattern of Gibbs free energy is also observed on inclusion of solvation effects (Supplementary Fig. 27). Figure $4 \mathrm{f}$ shows the DFT calculated diagram of Gibbs free energy of electroreduction of $\mathrm{CO}_{2}$ to formic acid over pristine and defect $\mathrm{Cu}_{2}(\mathrm{~L})$ with solvation effects considered. Furthermore, both $\mathrm{Cu}_{2}(\mathrm{~L})-\mathrm{t}$ and $\mathrm{Cu}_{2}(\mathrm{~L})$-e electrodes show an increase in uncoupled $\mathrm{Cu}(\mathrm{II})$ content during electrolysis (Fig. 4a), consistent with the increasing current density for $\mathrm{CO}_{2}$ reduction observed over the first hour of electrolysis. Hydrogen evolution was also interrogated by DFT calculations over pristine and defect $\mathrm{Cu}_{2}(\mathrm{~L})$ (Supplementary Fig. 28) confirming that the defect material will protonate more readily.

Conclusion. In summary, we have electrochemically prepared the $\mathrm{Cu}_{2}(\mathrm{~L})$-e/Cu electrode through controllable growth of MOF nanoparticles onto a $\mathrm{Cu}$-foam support. This integrated electrode composed of a thin compact coating of $\mathrm{Cu}_{2}(\mathrm{~L})$ on $\mathrm{Cu}$-foam incorporates uncoupled $\mathrm{Cu}(\mathrm{II})$ active sites and shows high conductivity and stability. This electrode shows excellent activity for the electro-reduction of $\mathrm{CO}_{2}$ to formic acid, with a low onset potential of $-1.45 \mathrm{~V}$ vs. $\mathrm{Ag} / \mathrm{Ag}^{+}$, and the $\mathrm{FE}_{\mathrm{HCOOH}}$ reaches $90.5 \%$ at $-1.80 \mathrm{~V}$ vs. $\mathrm{Ag} / \mathrm{Ag}^{+}$with a current density of $65.8 \mathrm{~mA} \cdot \mathrm{cm}^{-2}$. Experimental (EPR spectroscopy) and theoretical (DFT) methods 
confirm that the reaction is driven by defects within the structure of the decorated electrode. In $\mathrm{Cu}_{2}(\mathrm{~L})$-e/Cu these defects favour reduction of $\mathrm{CO}_{2}$ to formic acid versus $\mathrm{H}_{2}$ evolution. The facile preparation of $\mathrm{Cu}-\mathrm{MOF}-\mathrm{e} / \mathrm{Cu}$ electrodes offers an instructive pathway for the development of other efficient materials that catalyse $\mathrm{CO}_{2}$ reduction at less energetic potentials.

\section{Methods}

Materials. Ionic liquids (ILs), EmimOAc ( $>99 \%)$ and $\mathrm{EmimBF}_{4}(>99 \%)$ were purchased from Lanzhou Yulu Fine Chemical Co., Ltd. Other chemicals were obtained from Sigma-Aldrich Co., UK.

Ligand synthesis. The ligand $\mathrm{H}_{4} \mathrm{~L}$ was prepared by the published procedure ${ }^{30}$. 4Methylacetophenone $(13.4 \mathrm{~g}, 0.1 \mathrm{~mol})$, terephthalaldehyde $(2.70 \mathrm{~g}, 0.02 \mathrm{~mol})$ and $\mathrm{NaOH}$ powder $(5.10 \mathrm{~g}, 0.128 \mathrm{~mol})$ were combined and ground in a ball mill for 90 mins. The resultant solid was dissolved in EtOH $(600 \mathrm{~mL})$ with $\mathrm{NH}_{4} \mathrm{OAc}(30 \mathrm{~g}$, $0.39 \mathrm{~mol})$, and the solution heated under reflux for $24 \mathrm{~h}$. On cooling the white solid was collected by filtration and recrystallised from toluene to yield white crystals. This product $(3.0 \mathrm{~g})$ was combined with an aqueous solution of $\mathrm{HNO}_{3}(2 \mathrm{M}, 36$ $\mathrm{mL}$ ) and heated in an autoclave to $180^{\circ} \mathrm{C}$ for $24 \mathrm{~h}$. The reaction mixture was cooled to room temperature and the solid $\mathrm{H}_{4} \mathrm{~L}$ was collected and washed with distilled water until the filtrate was $\mathrm{pH}$ neutral. The solid was washed further with acetone and dried in vacuo.

Characterisations. The morphology of the materials was characterised on a SEM Quanta 650. PXRD analysis was performed on Rigaku Model D/MAX2500 diffractometer using $\mathrm{Cu}-\mathrm{Ka}$ radiation at a scan speed of $2 \% \mathrm{~min}$. Infrared spectra were collected on an iD5 ATR (Attenuated Total Reflection) instrument, and TGA was measured under $\mathrm{N}_{2}$ at a flow rate of $10 \mathrm{~mL} \cdot \mathrm{min}^{-1}$. EPR spectra at X-band and Qband were recorded using Bruker Micro spectrometers, and the intensity of the EPR signal of different samples was normalised to the sample quantity. The BET surface areas were obtained from $\mathrm{N}_{2}$ adsorption/desorption isotherms recorded on a Micromeritics 3-Flex instrument at $77 \mathrm{~K}$. $\mathrm{CO}_{2}$ adsorption isotherms were obtained using Micromeritics 3-Flex at $273 \mathrm{~K}, 283 \mathrm{~K}$ and $298 \mathrm{~K}$, and the value for $Q_{s t}$ for $\mathrm{CO}_{2}$ adsorption was estimated by fitting these isotherms to the Van t' Hoff equation. X-ray photoelectron spectroscopy (XPS) was performed on a Kratos Axis Ultra DLD spectrometer with a monochromated Al-Ka X-ray source $(E=1486.6$ $\mathrm{eV}, 10 \mathrm{~mA}$ emission). Fluorescence micrographs were recorded on an Olympus Fluoview FV-1000 instrument to measure the fluorescence generated by the oligomerisation of $1 \mathrm{~mL}$ furfuryl alcohol catalysed by $10 \mathrm{mg}$ of MOF at $60^{\circ} \mathrm{C}$ over $2 \mathrm{~h}$.

Solvothermal synthesis of $\mathbf{C u}_{\mathbf{2}}(\mathbf{L})-\mathbf{t}$. The solvothermal synthesis of $\mathrm{Cu}_{2}(\mathrm{~L})$ - $\mathrm{t}$ was conducted by following the literature method ${ }^{31} \cdot \mathrm{Cu}\left(\mathrm{NO}_{3}\right)_{2} \cdot 3 \mathrm{H}_{2} \mathrm{O}(24.2 \mathrm{mg}, 0.10$ $\mathrm{mmol})$ and $\mathrm{H}_{4} \mathrm{~L}(35.6 \mathrm{mg}, 0.05 \mathrm{mmol})$ were dissolved in DMF $(3 \mathrm{~mL})$ with $8 \mathrm{M}$ $\mathrm{HNO}_{3}(0.3 \mathrm{~mL})$. The solution was heated at $80^{\circ} \mathrm{C}$ for $48 \mathrm{~h}$ in a pressure tube. On cooling to room temperature, the precipitate was collected by centrifugation, washed five times with acetone $(10 \mathrm{~mL})$ and dried in vacuo.

Electro-preparation of $\mathbf{C u}_{\mathbf{2}}(\mathbf{L})-\mathbf{e} / \mathbf{C u}$. This was performed in a $50 \mathrm{~mL}$ single cell using a two-electrode system comprising $\mathrm{Cu}$ foam sheets $\left(0.5 \mathrm{~cm} \times 1.0 \mathrm{~cm}^{2}\right)$ as both cathode and anode with a solution of DMF/dioxane $/ \mathrm{H}_{2} \mathrm{O}(2: 1: 1 \mathrm{v} / \mathrm{v} / \mathrm{v} ; 50 \mathrm{~mL}$ with 5 drops of aqueous $\mathrm{HCl}(37 \%)$ containing EmimOAc $(1.0 \mathrm{~mL})$ as supporting electrolyte. $\mathrm{H}_{4} \mathrm{~L}$ ( $33 \mathrm{mg}, 0.05 \mathrm{mmol}$ ) was dissolved in the electrolyte solution under stirring to form a homogeneous solution. The electrolysis was undertaken for $10 \mathrm{~min}$ at $8.0 \mathrm{~V}$ and $60^{\circ} \mathrm{C}$. The as-synthesised MOF-decorated electrode was immersed in a mixture of acetone/acetonitrile $(1: 1 \mathrm{v} / \mathrm{v})$ and the solvent exchanged five times to remove any residual electrolyte and unreacted materials. The preparation of HKUST-1-e/Cu electrode was undertaken using the same method as used for $\mathrm{Cu}_{2}(\mathrm{~L})$-e/Cu but using a different ligand (trimesic acid).

Preparation of electrodes. The $\mathrm{Cu}_{2}(\mathrm{~L})$-e/Cu and HKUST-1-e/Cu were used directly as electrodes. For the $\mathrm{Cu}_{2}(\mathrm{~L})$ - $\mathrm{t} / \mathrm{CP}$ electrode, $5.0 \mathrm{mg}$ of $\mathrm{Cu}_{2}(\mathrm{~L})$ - $\mathrm{t}$ were suspended in $0.5 \mathrm{~mL}$ of isopropanol containing $25 \mu \mathrm{L}$ of Nafion D-521 dispersion ( $5 \mathrm{wt} \%$ ) and treated with ultrasound to form a homogeneous ink. $150 \mu \mathrm{L}$ of the ink was spread onto the hydrophobic CP $\left(0.5 \times 0.5 \mathrm{~cm}^{2}\right)$ surface and dried at $60^{\circ} \mathrm{C}$.

Electrochemical reduction of $\mathbf{C O}_{2}$. The electro-reduction of $\mathrm{CO}_{2}$ was carried out on an electrochemical workstation (CHI 660E, USA). LSV and electrolysis were conducted in an $\mathrm{H}$-type cell with a three-electrodes configuration consisted of working electrode, $\mathrm{CP}\left(0.5 \times 0.5 \mathrm{~cm}^{2}\right)$ as counter electrode, and $\mathrm{Ag} / \mathrm{Ag}^{+}(0.01 \mathrm{M}$ $\mathrm{AgNO}_{3}$ in $0.1 \mathrm{M}$ TBAP-MeCN) as reference electrode ${ }^{12}$. The catholyte and anolyte were $0.5 \mathrm{M} \mathrm{EmimBF}_{4} / \mathrm{MeCN}$ and $0.1 \mathrm{M} \mathrm{H}_{2} \mathrm{SO}_{4}$ aqueous solution, respectively, separated by a Nafion-115 membrane. $\mathrm{N}_{2}$ and $\mathrm{CO}_{2}$ were bubbled into the catholyte prior to the experiments. For cyclic voltammetric measurements, a scan speed of $20 \mathrm{mV} \cdot \mathrm{s}^{-1}$ was used over a potential range from $-1.2 \mathrm{~V}$ to $-2.4 \mathrm{~V}$ vs. $\mathrm{Ag} / \mathrm{Ag}^{+}$.
Electrolysis experiments were performed with an initial $\mathrm{CO}_{2}$ flow rate of $20 \mathrm{~mL}$ $\min ^{-1}$ prior to the experiment, which was decreased to $10 \mathrm{~mL} \mathrm{~min}^{-1}$ after the electrolyte was saturated with $\mathrm{CO}_{2}$. After electrolysis, the gaseous products were collected using a gas bag and analysed by GC and liquid products measured by ${ }^{1} \mathrm{H}$ NMR spectroscopy. The Faradaic efficiencies (FE) were calculated using the Eq. (1)

$$
\mathrm{FE}(\%)=\frac{n_{\text {product }} \times n_{\text {electrons }} \times F}{Q} \times 100 \%
$$

where $n_{\text {product }}$ is the amount of product (mol) from GC $\left(\mathrm{H}_{2}\right)$ or ${ }^{1} \mathrm{H}$ NMR spectroscopy (formic acid), $n_{\text {electrons }}$ is electron transfer number (both the production of $\mathrm{H}_{2}$ and $\mathrm{HCOOH}$ are two-electron processes), $F$ is the Faraday constant $\left(96485 \mathrm{C} \mathrm{mol}^{-1}\right)$, and $Q$ is the total charge passed during the electrolysis of $\mathrm{CO}_{2}$. The current density for a given product is calculated by multiplying the total current density with FE of the product. The $\mathrm{C}_{\mathrm{dl}}$ was determined by measuring $\mathrm{CV}$ curves at different scan rates. The potential range for the $\mathrm{CV}$ tests was from $-0.55 \mathrm{~V}$ to $-0.50 \mathrm{~V}$ vs. $\mathrm{Ag} / \mathrm{Ag}^{+}$. The EIS spectra were recorded at open circuit potential with an amplitude of $5.0 \mathrm{mV}\left(10^{-2}\right.$ to $\left.10^{5} \mathrm{~Hz}\right)$, and the value for $R_{\mathrm{ct}}$ obtained by fitting the EIS spectra using the Zview software (Version 3.1, Scribner Associates, USA) ${ }^{12,38}$

EPR analysis. EPR spectra were recorded at room temperature, in continuouswave mode, on Bruker EMX spectrometers (X-band, ca. $9.85 \mathrm{GHz}$; Q-band, ca. 34 $\mathrm{GHz}$ ), at mw power of $\sim 0.63 \mathrm{~mW}$ and modulation amplitude $10 \mathrm{G}$; spectra reported herein were typically obtained over an average of 20 scans, and a Bruker strong pitch $(g=2.0028)$ reference was used as a calibrator. Theoretical modelling of the spectra was performed with the EasySpin toolbox within Matlab ${ }^{49}$. The intensity of the EPR signal of different samples was normalised to the quantity of sample.

Calculations of the spectra with EasySpin ${ }^{36}$ using the iterative spin Hamiltonian in the Eq. $(2)^{34,50 \text { : }}$

$$
\hat{H}=g \beta B \hat{S}+D\left[\hat{S}_{z}^{2}-2 / 3\right]+E\left(\hat{S}_{x}^{2}+\hat{S}_{y}^{2}\right)
$$

where $D$ and $E$ are the axial and rhombic zero-field splitting parameters, respectively, to give $g_{\mathrm{xx}}=g_{\mathrm{yy}}=2.06-2.07, g_{\mathrm{zz}}=2.31-2.36, D=0.33-0.35 \mathrm{~cm}^{-1}$ and $E=0$ (Fig. $2 \mathrm{~g}$ and Supplementary Figs. 5 and 6 and Supplementary Table 2). These parameters are in excellent agreement with data for binuclear copper acetate ${ }^{35}$ and other $\mathrm{Cu}(\mathrm{II})$ systems with a $\left[\mathrm{Cu}_{2}(\mathrm{OOCR})_{4}\right]$ paddle wheel structure ${ }^{36,51}$

The relative content of monomer [uncoupled $\mathrm{Cu}(\mathrm{II})$ centre as defect] and binuclear $\left\{\right.$ within $\left[\mathrm{Cu}_{2}(\mathrm{OOCR})_{4}\right]$ paddlewheels $\}$ centres was calculated from the second integrals from simulated EPR Q-band spectra. At Q-band, the entire $S=$ 1 spectrum of the binuclear unit is observed hence defining its relative weighting better than that at X-band where the zero-field splitting is comparable to the microwave frequency. The ratio of monomer to binuclear species is obtained from the weighting of the two spin systems (Supplementary Fig. 7; this is illustrated by the second integrals of the simulated components in Supplementary Fig. 8) ${ }^{36}$. The final monomer to binuclear ratio was obtained by weighting the EPR data by the Boltzmann population of the $S=1$ state of the binuclear species based upon the Bleaney-Bower equation [(Eq. (3) $]^{35,36}$

$$
\frac{n T}{n T+n S}=\frac{3 \exp \left(\frac{-\Delta E_{S T}}{R T}\right)}{1+3 \exp \left(\frac{-\Delta E_{S T}}{R T}\right)}
$$

where $\Delta E_{S T}$ is the singlet (S)-triplet (T) energy gap (ca. $\left.300 \mathrm{~cm}^{-1}\right), n T$ and $n S$ are the populations at temperature of $T$, and $R$ is the gas constant.

The relative content of free, uncoupled $\mathrm{Cu}$ (II) centres as a function of electrolysis time was measured from the second integral of the signal for this species using X-band EPR spectroscopy. EPR spectra of electrodes were collected every 15 min during electrolysis at $-1.8 \mathrm{~V}$ vs. $\mathrm{Ag} / \mathrm{Ag}^{+}$. The obtained EPR spectra were transformed to a second integral value, and all data normalised to the surface area of the electrodes.

DFT calculations. Calculations were based on spin-polarised DFT using projector augmented wave (PAW) methods, as implemented in the Vienna ab initio simulation package (VASP) ${ }^{52}$. A plane-wave basis set with a kinetic-energy cut-off of $400 \mathrm{eV}$ was used to expand the wave function of valence electrons. The generalised gradient approximation (GGA) with the Perdew-Burke-Ernzerhof (PBE) functional was used for describing the exchange-correlation interactions ${ }^{53}$. Vacuum space of $20 \AA$ was set to prevent the interaction between two molecules. The Brillouin-zone integration was sampled by single $\Gamma$ point. The structural relaxations were performed by computing the Hellmann-Feynman forces within the total energy and force convergences of $10^{-4} \mathrm{eV}$ and $0.01 \mathrm{eV} / \AA$, respectively. Based on computational hydrogen electrode (CHE) $\operatorname{model}^{54}$, and the Gibbs free energy of an adsorbed intermediate from reduced $\mathrm{CO}_{2}$ was calculated using $\Delta \mathrm{G}=\Delta \mathrm{E}+$

$\Delta \mathrm{E}_{\mathrm{ZPE}}-\mathrm{T} \Delta \mathrm{S}_{\mathrm{ads}}$, where $\Delta \mathrm{E}, \Delta \mathrm{E}_{\mathrm{ZPE}}$ and $\mathrm{T} \Delta \mathrm{S}_{\mathrm{ads}}$ are the electronic adsorption energy, zero point energy and entropy corrections, respectively. The corrections of zero point energy and entropy of different species are shown in Supplementary Table 4. Vaspsol, the Poisson-Boltzmann implicit solvation model, was used to describe the effect of solvation ${ }^{55}$, and DFT calculations were implemented via VASP with a 
dielectric constant of $\varepsilon=37.5$. The solvation energy was directly contained in the total energy.

\section{Data availability}

All relevant data are available from the authors, and/or are included with the manuscript. All other data supporting the findings of this study are available within the Article and its Supplementary Information, or from the corresponding author upon reasonable request.

Received: 11 May 2020; Accepted: 22 September 2020;

Published online: 29 October 2020

\section{References}

1. Appel, A. M. et al. Frontiers, opportunities, and challenges in biochemical and chemical catalysis of $\mathrm{CO}_{2}$ fixation. Chem. Rev. 113, 6621-6658 (2013).

2. Aresta, M., Dibenedetto, A. \& Angelini, A. Catalysis for the valorization of exhaust carbon: from $\mathrm{CO}_{2}$ to chemicals, materials, and fuels. Technological use of $\mathrm{CO}_{2}$. Chem. Rev. 114, 1709-1742 (2014).

3. Dalle, K. E. et al. Electro- and solar-driven fuel synthesis with first row transition metal complexes. Chem. Rev. 119, 2752-2875 (2019)

4. Liu, J., Thallapally, P. K., McGrail, B. P., Brown, D. R. \& Liu, J. Progress in adsorption-based $\mathrm{CO}_{2}$ capture by metal-organic frameworks. Chem. Soc. Rev. 41, 2308-2322 (2012).

5. Wickramaratne, N. P. et al. Nitrogen enriched porous carbon spheres: attractive materials for supercapacitor electrodes and $\mathrm{CO}_{2}$ adsorption. Chem. Mater. 26, 2820-2828 (2014)

6. Sun, X. F. et al. MoP nanoparticles supported on indium-doped porous carbon: outstanding catalysts for highly efficient $\mathrm{CO}_{2}$ electroreduction. Angew. Chem. Int. Ed. 57, 2427-2431 (2018).

7. He, M. Y., Sun, Y. H. \& Han, B. X. Green carbon science: scientific basis for integrating carbon resource processing, utilization, and recycling. Angew. Chem. Int. Ed. 52, 9620-9633 (2013).

8. Nam, D. H. et al. Molecular enhancement of heterogeneous $\mathrm{CO}_{2}$ reduction Nat. Mater. 19, 266-276 (2020).

9. Andrei, V., Reuillard, B. \& Reisner, E. Bias-free solar syngas production by integrating a molecular cobalt catalyst with perovskite- $\mathrm{BiVO}_{4}$ tandems. Nat. Mater. 19, 189-194 (2020).

10. Dinh, C. T. et al. $\mathrm{CO}_{2}$ electroreduction to ethylene via hydroxide-mediated copper catalysis at an abrupt interface. Science 360, 783-787 (2018).

11. Wang, Y. R. et al. Oriented electron transmission in polyoxometalatemetalloporphyrin organic framework for highly selective electroreduction of $\mathrm{CO}_{2}$. Nat. Commun. 9, 4446 (2018).

12. Kang, X. C. et al. Highly efficient electrochemical reduction of $\mathrm{CO}_{2}$ to $\mathrm{CH}_{4}$ in an ionic liquid using a metal-organic framework cathode. Chem. Sci. 7, 266-273 (2016).

13. Deng, W. Y. et al. Crucial role of surface hydroxyls on the activity and stability in electrochemical $\mathrm{CO}_{2}$ reduction. J. Am. Chem. Soc. 141, 2911-2915 (2019).

14. Wakerley, D. et al. Bio-inspired hydrophobicity promotes $\mathrm{CO}_{2}$ reduction on a Cu surface. Nat. Mater. 18, 1222-1227 (2019).

15. Zhu, Q. G. et al. Carbon dioxide electroreduction to $C_{2}$ products over coppercuprous oxide derived from electrosynthesized copper complex. Nat. Commun. 10, 3851 (2019).

16. Dutta, A., Rahaman, M., Luedi, N. C., Mohos, M. \& Broekmann, P. Morphology matters: tuning the product distribution of $\mathrm{CO}_{2}$ electroreduction on oxide-derived cu foam catalysts. ACS Catal. 6, 3804-3814 (2016).

17. $\mathrm{Wu}, \mathrm{J}$. X. et al. Cathodized copper porphyrin metal-organic framework nanosheets for selective formate and acetate production from $\mathrm{CO}_{2}$ electroreduction. Chem. Sci. 10, 2199-2205 (2019).

18. Nam, D. H. et al. Metal-organic frameworks mediate cu coordination for selective $\mathrm{CO}_{2}$ electroreduction. J. Am. Chem. Soc. 140, 11378-11386 (2018).

19. Bulushev, D. A. \& Ross, J. R. H. Towards sustainable production of formic acid from biomass for getting hydrogen and fuels. ChemSusChem 11, 821-836 (2018).

20. Sun, Z. Y., Ma, T., Tao, H. C., Fan, Q. \& Han, B. X. Fundamentals and challenges of electrochemical $\mathrm{CO}_{2}$ reduction using two-dimensional materials. Chem 3, 560-587 (2017)

21. Nitopi, $\mathrm{S}$. et al. Progress and perspectives of electrochemical $\mathrm{CO}_{2}$ reduction on copper in aqueous electrolyte. Chem. Rev. 119, 7610-7672 (2019).

22. Li, C. W., Ciston, J. \& Kanan, M. W. Electroreduction of carbon monoxide to liquid fuel on oxide-derived nanocrystalline copper. Nature 508, 504-507 (2014).

23. Li, C. W. \& Kanan, M. W. $\mathrm{CO}_{2}$ reduction at low overpotential on $\mathrm{Cu}$ electrodes resulting from the reduction of thick $\mathrm{Cu}_{2} \mathrm{O}$ films. J. Am. Chem. Soc. 134, 7231-7234 (2012)
24. Huang, Y. B., Liang, J., Wang, X. S. \& Cao, R. Multifunctional metal-organic framework catalysts: synergistic catalysis and tandem reactions. Chem. Soc. Rev. 46, 126-157 (2017)

25. Han, X., Yang, S. \& Schröder, M. Porous metal-organic frameworks as emerging sorbents for clean air. Nat. Rev. Chem. 3, 108-118 (2019).

26. Easun, T. L., Moreau, F., Yan, Y., Yang, S. \& Schröder, M. Structural and dynamic studies of substrate binding in porous metal-organic framework materials. Chem. Soc. Rev. 46, 239-274 (2017).

27. Li, L. J. et al. Metal-organic frameworks: a promising platform for constructing non-noble electrocatalysts for the oxygen-reduction reaction. J. Mater. Chem. A 7, 1964-1988 (2019).

28. Liu, T. et al. CoP-doped MOF-based electrocatalyst for $\mathrm{pH}$-universal hydrogen evolution reaction. Angew. Chem. Int. Ed. 58, 4679-4684 (2019).

29. Zhao, S. L. et al. Ultrathin metal-organic framework nanosheets for electrocatalytic oxygen evolution. Nat. Energy 1, 1-10 (2016).

30. Carter, J. H. et al. Exceptional adsorption and binding of sulfur dioxide in a robust zirconium-based metal-organic framework. J. Am. Chem. Soc. 140, 15564-15567 (2018).

31. Verma, G. et al. Partially interpenetrated $\mathrm{NbO}$ topology metal-organic framework exhibiting selective gas adsorption. Cryst. Growth Des. 17, 2711-2717 (2017)

32. Ameloot, R. et al. Patterned growth of metal-organic framework coatings by electrochemical synthesis. Chem. Mater. 21, 2580-2582 (2009).

33. Kang, X. C. et al. Integration of mesopores and crystal defects in metal-organic frameworks via templated electrosynthesis. Nat. Commun. 10, 4466 (2019).

34. Mkami H., E. L. et al. EPR and magnetic studies of a novel copper metal organic framework (STAM-I). Chem. Phys. Lett. 544, 17-21 (2012).

35. Karunakaran, C. \& Balamurugan, M. Spin Resonance Spectroscopy. 169-197 (Elsevier Inc., 2018).

36. Bleaney, B. \& Bowers, K. D. Anomalous paramagnetism of copper acetate. Proc. R. Soc. Lond. A 214, 451-465 (1952).

37. Albo, J. et al. Copper-based metal-organic porous materials for $\mathrm{CO}_{2}$ electrocatalytic reduction to alcohols. ChemSusChem 10, 1100-1109 (2017).

38. Zhu, Q. G. et al. Efficient Reduction of $\mathrm{CO}_{2}$ into formic acid on a lead or tin electrode using an ionic liquid catholyte mixture. Angew. Chem. Int. Ed. 55, 9012-9016 (2016)

39. Wu, H. R. et al. Design of naturally derived lead phytate as an electrocatalyst for highly efficient $\mathrm{CO}_{2}$ reduction to formic acid. Green. Chem. 20, 4602-4606 (2018).

40. $\mathrm{Lu}, \mathrm{L}$. et al. Selective electroreduction of carbon dioxide to formic acid on electrodeposited $\mathrm{SnO}_{2} @ \mathrm{~N}$-doped porous carbon catalysts. Sci. China Chem. 61, 228-235 (2018)

41. Jee, B. et al. Continuous wave and pulsed electron spin resonance spectroscopy of paramagnetic framework cupric ions in the $\mathrm{Zn}(\mathrm{II})$ doped porous coordination polymer $\mathrm{Cu}_{3-\mathrm{x}} \mathrm{Zn}_{\mathrm{x}}(\mathrm{btc})_{2}$. J. Phys. Chem. C. 114, 16630-16639 (2010).

42. Song, D. et al. Coordinative reduction of metal nodes enhances the hydrolytic stability of a paddlewheel metal-organic framework. J. Am. Chem. Soc. 141, 7853-7864 (2019)

43. Gao, S. et al. Partially oxidized atomic cobalt layers for carbon dioxide electroreduction to liquid fuel. Nature 529, 68-71 (2016).

44. Wang, X. L. et al. Exploring the performance improvement of the oxygen evolution reaction in a stable bimetal-organic framework system. Angew. Chem. Int. Ed. 57, 9660-9664 (2018).

45. Zhang, L., Zhao, Z. J. \& Gong, J. L. Nanostructured materials for heterogeneous electrocatalytic $\mathrm{CO}_{2}$ reduction and their related reaction mechanisms. Angew. Chem. Int. Ed. 56, 11326-11353 (2017).

46. Feaster, J. T. et al. Understanding selectivity for the electrochemical reduction of carbon dioxide to formic acid and carbon monoxide on metal electrodes. ACS Catal. 7, 4822-4827 (2017).

47. Kortlever, R., Shen, J., Schouten, K. J. P., Calle-Vallejo, F. \& Koper, M. T. M. Catalysts and reaction pathways for the electrochemical reduction of carbon dioxide. J. Phys. Chem. Lett. 6, 4073-4082 (2015).

48. Dong, H. L., Li, Y. Y. \& Jiang, D. E. First-principles insight into electrocatalytic reduction of $\mathrm{CO}_{2}$ to $\mathrm{CH}_{4}$ on a copper nanoparticle. J. Phys. Chem. C. 122, 11392-11398 (2018)

49. Stoll, S. \& Britt, R. D. General and efficient simulation of pulse EPR spectra. Phys. Chem. Chem. Phys. 11, 6614-6625 (2009).

50. Malik, M. A. et al. The synthesis, spectroscopy and X-ray single crystal structure of catena- $[(\mu$-anacardato)-copper(II)bipyridine] [Cu2 $\{(\mu-\mathrm{O} 2 \mathrm{CC} 6 \mathrm{H} 3$ (o-OH)(o-C15H31)\}4(NC5H5)2]. Dalton Trans. 42, 14438-14444 (2013).

51. Güdel, H., Stebler, A. \& Furrer, A. Direct observation of singlet-triplet separation in dimeric copper(II) acetate by Neutron Inelastic Scattering spectroscopy. Inorg. Chem. 18, 1021-1023 (1979).

52. Kresse, G. \& Joubert, D. From ultrasoft pseudopotentials to the projector augmented-wave method. Phys. Rev. B 59, 1758-1775 (1999).

53. Perdew, J. P., Burke, K. \& Ernzerhof, M. Generalized gradient approximation made simple. Phys. Rev. Lett. 77, 3865-3868 (1996). 
54. Nørskov, J. K. et al. Origin of the overpotential for oxygen reduction at a fuelcell cathode. J. Phys. Chem. B 108, 17886-17892 (2004).

55. Mathew, K., Sundararaman, R., Letchworth-weaver, K., Arias, T. A. \& Hennig, R. G. Implicit solvation model for density-functional study of nanocrystal surfaces and reaction pathways. J. Chem. Phys. 140, 084106 (2014).

\section{Acknowledgements}

We thank EPSRC (EP/I011870), the Royal Society (IC170327), National Natural Science Foundation of China $(21733011,21890761)$, University of Manchester and Institute of Chemistry, Chinese Academy of Sciences for funding, and EPSRC for funding of the EPSRC National EPR Facility at Manchester. This project has received funding from the European Research Council (ERC) under the European Union's Horizon 2020 research and innovation programme (grant agreement No 742401, NANOCHEM). J.L. thanks China Scholarship Council for funding. X.K. and A.S. are supported by Royal Society Newton International Fellowships. We thank Dr. M. Shanmugam, Mr. A. Brookfield and Dr. S. Lockyer for their kind support with some of the EPR measurements.

\section{Author contributions}

X.K., L.Li, X.H., J.L. and L.Liu: syntheses and characterisations of MOF samples and catalysis studies. L.Li, A.S., F.T. and E.J.L.M.: collection and analysis of EPR data. X.K. and B.H.: DFT calculation. B.H., S.Y. and M.S.: overall design and direction of the project. X.K., B.H., S.Y. and M.S.: preparation of the manuscript with help from all authors.

\section{Competing interests}

The authors declare no competing interests.

\section{Additional information}

Supplementary information is available for this paper at https://doi.org/10.1038/s41467 020-19236-4.

Correspondence and requests for materials should be addressed to B.H.; , S.Y.; or M. Söd.

Peer review information: Nature Communications thanks Zhi-Yuan Gu, Hervé Vezin and the other, anonymous, reviewer(s) for their contribution to the peer review of this work. Peer reviewer reports are available.

Reprints and permission information is available at http://www.nature.com/reprints

Publisher's note Springer Nature remains neutral with regard to jurisdictional claims in published maps and institutional affiliations.

\begin{abstract}
(c) (i) Open Access This article is licensed under a Creative Commons Attribution 4.0 International License, which permits use, sharing, adaptation, distribution and reproduction in any medium or format, as long as you give appropriate credit to the original author(s) and the source, provide a link to the Creative Commons license, and indicate if changes were made. The images or other third party material in this article are included in the article's Creative Commons license, unless indicated otherwise in a credit line to the material. If material is not included in the article's Creative Commons license and your intended use is not permitted by statutory regulation or exceeds the permitted use, you will need to obtain permission directly from the copyright holder. To view a copy of this license, visit http://creativecommons.org/ licenses/by/4.0/.
\end{abstract}

(C) The Author(s) 2020 